\title{
Cytogenetic Effects of Gamma Irradiated Stored Seeds of Trigonella foenum graecum
}

\author{
K. Mishra' and S. S. Raghuvanshi \\ Department of Botany, Lucknow University, Lucknow, India
}

Accepted September 10, 1987

Cytogenetical changes occurring due to the effect of age of seed on gamma ray induced chromosome aberrations have been described in detail by a number of workers. Cärtledge and Blakeslee (1934) studied the effects of aging on Datura seeds, Nawaschin (1933) and Nawaschin and Gerassimowa (1936) reported the effects of aging on Crepis seed. Gustafsson (1944) studied the effects of age on the seeds of barley and reported number of disturbed cells in the first mitotic division after germination. Nichols (1941) has reported spontaneous aberrations and the effects of aging on Allium seeds as determined from examination of the first mitotic divisions. Nilan and Gunthardt (1953) indicated that germinability of seeds decreases and chromosome aberration frequency increases with age and with $\mathrm{X}$-ray dose.

Present paper describes cytogenetic changes occurring due to the storage of Trigonella foenum graecum seeds after gamma irradiation.

The system tested gives excellent mass of proliferating cells which is easy in handling. Other than that it is economically very important as it yields many important alkaloids.

\section{Materials and methods}

200 seeds of $2 \mathrm{n}$ and $4 \mathrm{n} T$. foenum graecum were irradiated at $20 \mathrm{~K} \mathrm{rad}, 40 \mathrm{~K} \mathrm{rad}$ and $60 \mathrm{~K}$ rad of gamma rays. Seeds were divided into lots after irradiation. First lot was studied immediately after irradiation and second set after 6 month storage. Materials were sampled from root tips of control and treated seeds. These root tips were fixed in freshly prepared Carnoy's fixative (alcohol: acetic acid, $3: 1$ ) and stained with haemotoxylin stain (Darlington and LaCour 1976). Mitotic index and chromosomal aberrations were observed in each set and were used as criteria to measure their relative biological response.

\section{Results}

Analysis of mitotic index (Table 1) showed dose dependent relationship as higher doses caused increase in mitotic index. Mitotic index was higher in second set in comparison of first set at all the doses applied in $2 \mathrm{n}$ and $4 \mathrm{n}$.

Table 1. Mitotic index (AM \pm ES values) in root tips of $T$. foenum graecum exposed to 20,40 and $60 \mathrm{~K}$ rad of gamma rays

\begin{tabular}{|c|c|c|c|c|}
\hline & $2 n$ & $4 n$ & $2 n$ & $4 n$ \\
\hline Control & $6.366 \pm 0.789$ & $5.582 \pm 0.667$ & $4.604 \pm 0.7115$ & $4.846 \pm 0.5475$ \\
\hline $20 \mathrm{~K} \mathrm{rad}$ & $3.953 \pm 0.599$ & $2.309 \pm 0.797$ & $3.806 \pm 0.0476$ & $4.316 \pm 0.6592$ \\
\hline $40 \mathrm{~K} \mathrm{rad}$ & $5.647 \pm 0.3592$ & $6.037 \pm 0.648$ & $4.722 \pm 0.3130$ & $5.402 \pm 0.2351$ \\
\hline $60 \mathrm{~K} \mathrm{rad}$ & $5.609 \pm 0.880$ & $7.516 \pm 0.2987$ & $5.078 \pm 0.3450$ & $5.324 \pm 0.6114$ \\
\hline
\end{tabular}

Data obtained from 8,000 to 10,000 cells taken from ten root tips selected at random.

1 To whom all correspondence should be addressed: Kumkum Mishra, Industrial Toxicology Research Centre, Post Box 80, Mahatma Gandhi Marg, Lucknow-226 001, India. 
Table 2. Abnormal cell index ( $\mathrm{AM} \pm \mathrm{SE}$ value) in root tips of $\boldsymbol{T}$. foenum graecum exposed to 20,40 and $60 \mathrm{~K}$ rad of gamma rays

\begin{tabular}{|c|c|c|c|c|}
\hline & $2 n$ & $4 n$ & $2 n$ & $4 n$ \\
\hline $20 \mathrm{~K} \mathrm{rad}$ & $0.482 \pm 0.124$ & $0.52 \pm 0.115$ & $.256 \pm 0.012$ & $.089 \pm 0.063$ \\
\hline $40 \mathrm{~K} \mathrm{rad}$ & $1.098 \pm 0.1503$ & $1.55 \pm 0.2036$ & $.207 \pm 0.46$ & $.381 \pm 0.047$ \\
\hline $60 \mathrm{~K} \mathrm{rad}$ & $1.632 \pm 0.3096$ & $2.25 \pm 0.1932$ & $.308 \pm 0.519$ & $.838 \pm 0.176$ \\
\hline
\end{tabular}
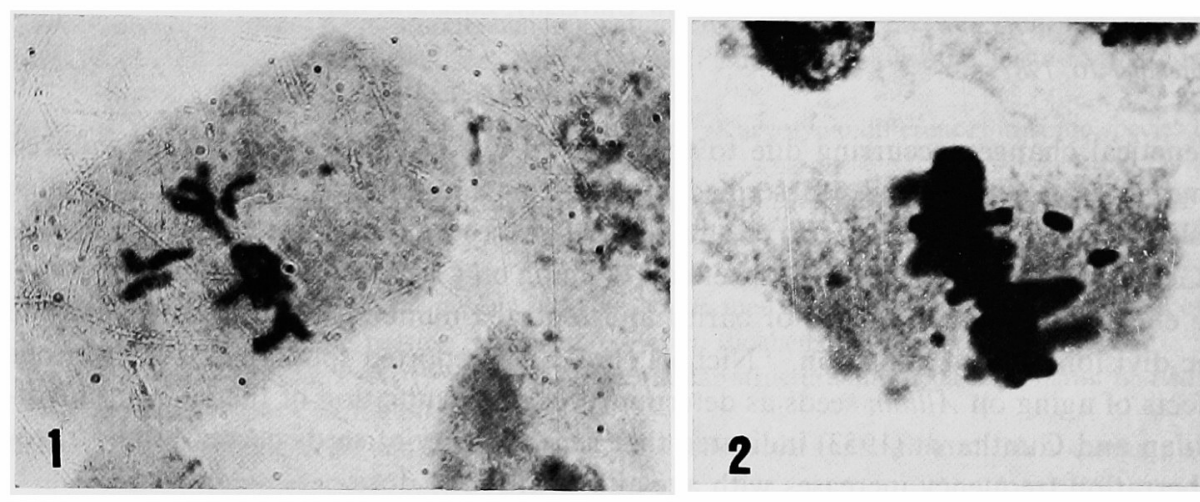

2
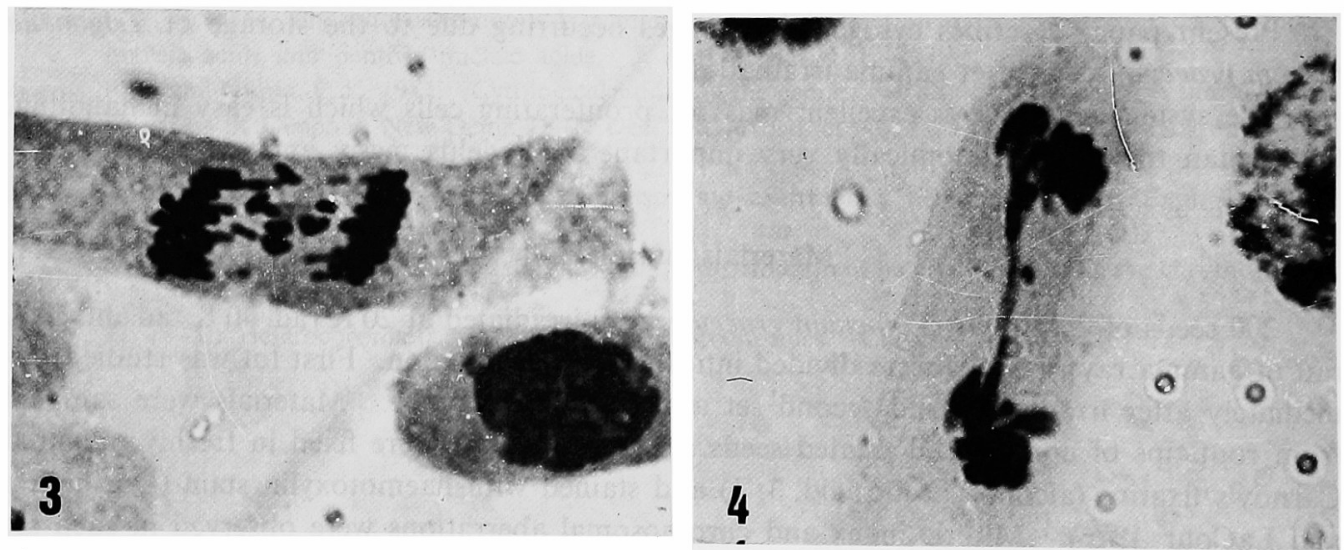

Figs. 1-4. Aberrations induced by gamma irradiations in root tip cell of $T$. foenum graecum. 1 , stray in metaphase. 2, fragment in metaphase. 3, fragments and laggards in anaphase. 4, chromosomal bridge. Magnification at $3000 \times$

Table 3. Chromosomal aberration per cell in root tips of $T$. foenum graecum exposed to 20,40 and $60 \mathrm{~K}$ rad of gamma rays

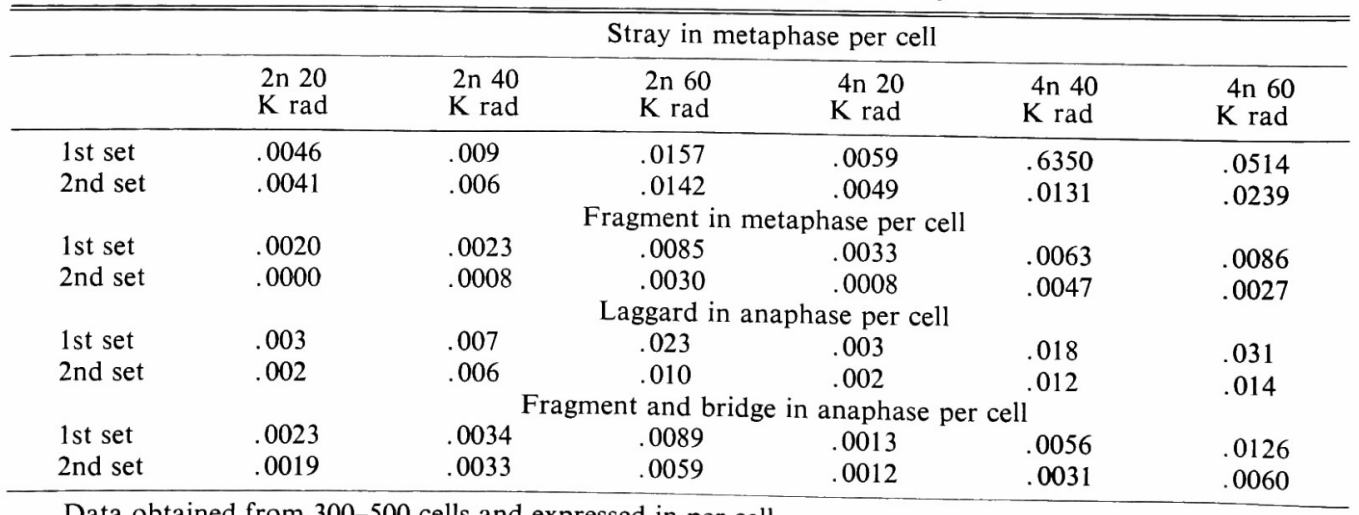

Data obtained from 300-500 cells and expressed in per cell. 
Abnormal cell index (Table 2) showed that $4 \mathrm{n}$ have more aberrant cell as compare to $2 \mathrm{n}$. Abnormal cells are decreasing with the passage of time from first upto second set.

Stray in metaphase (Fig. 1, Table 3): Their frequency increased gradually with increase in dose from 20 upto $60 \mathrm{~K}$ rad in diploid as well as tetraploid in first and second set. But from 1 st to 2 nd set, with the passage of time decrease in stray was observed.

Fragmentation in metaphase (Fig. 2, Table 3): Fragmentation was seen gradually increased in both $2 \mathrm{n}$ and $4 \mathrm{n}$ doses. But with the passage of time from 1 st to 2 nd set there was gradual decrease in number of fragments per cell in $2 n$ as well as in $4 n$.

Laggard in anaphase (Fig. 3, Table 3): In both the sets their frequency increased gradually with dose. But there was decrease in 2 nd set in comparision of 1 st set after 6 month.

Fragment and bridge in anaphase (Fig. 4, Table 3): These increase gradually with dose in both the sets in diploid as well as tetraploid. But with the passage of time there was gradual decrease in diploid from 1 st to 2 nd set.

\section{Discussion}

It is very much evident from our data that increase in mitotic index was directly proportional to increase in dose in all the sets in diploid and tetraploid. With the passage of time from 1st upto 2 nd set the mitotic index was increasing gradually and showing stimulatory effect of gamma irradiated stored seeds. Our findings are parallel to those of Carlson et al. (1953), who attributed the increased mitotic activity after irradiation to be a simultaneous release from an inhibition of a population of cells which is accumulated in prophase.

Kothekar (1978) observed enhanced frequency of cells in mitosis with physical and chemical mutagen treatment in Solanum nigrum. Different types of chromosomal aberrations as fragments, stray, bridges and laggards were observed. Such type of aberrations were observed by Prasad and Godward (1974). Several theories have been put forth by the earlier workers to explain the mechanism of chromosome breakage and production of different types of chromosomal aberrations in mitosis (Sax 1941) and Mikaelsen et al. (1968). In case of Trigonella foenum graecum radiation treatments have been responsible for the breaks in chromosome and discrepancies in spindle formation. Increase in the chromosomal aberration frequency in mitosis with increase in doses of gamma rays might perhaps be due to the interactions of ionizing particles or free radicals with the protoplasm mediated by excitations or ionizations either directly or indirectly which ultimately have increased aberration frequency. The aberrations per cell and abnormal cells are decreasing with the passage of time from 1 st to 2 nd set. Radiobiological damage may be repaired from the internal radioactivity and transmutation of internal elements.

Number of chromosomal aberrations per cell was higher in tetraploid in comparison of diploid in both the sets. Tetraploid of $T$. foenum graecum has higher ICV as Interphase chromosome volume than diploid (Raghuvanshi and Singh 1977). ICV of diploid were found to be $11.96 \pm .01 \mu^{3}$ while those of tetraploid were $18.2 \pm .15 \mu^{3}$. Higher frequency of chromosomal aberration in tetraploid at different doses may be due to greater ICV which offer more target area for radiation damage.

\section{Summary}

Gamma irradiation is one of the most important physical mutagens which is used for cytogenetic effects. The cytogenetic changes occurring due to the storages of Trigonella foenum graecum seeds ( $2 \mathrm{n}$ and $4 \mathrm{n}$ ) after gamma irradiation were investigated. This treatment 
accelerated the mitosis and decreased chromosomal aberrations in $2 \mathrm{n}$ as well as in $4 \mathrm{n}$. Chromosomal changes produced comprised of fragments and stray in metaphase cell, laggards, fragments and bridges in anaphase. Appearance of higher frequency of aberrations per cell in tetraploid indicated that tetraploids were more sensitive to gamma irradiation rather than diploid. This study also reveals that storage of seeds after gamma irradiation may lead to genetic repairing.

\section{References}

Carlson, J. G., Harrington, N. G. and Gaulden, M. E. 1953. Mitotic effects of prolonged irradiation with low intensity gamma rays on the chrotophase neuroblast. Biol. Bull. 104: 313-325.

Cartledge, J. L. and Blakeslee, A. F. 1978. Mutation rate increased by aging seeds as shown by pollen abortion. Proc. Nat. Acad. Science 20: 103-110.

Darlington, C. D. and LaCour, L. F. 1976. The Handling of Chromosomes. Allen and Unwin, London.

Gustafsson, A. 1944. The X-rays resistance of dormant seeds in agriculture plants. Hereditas 30: 165-178.

Kothekar, V.S. 1978. Cytogenetic studies on Solanum nigram Linn. Ph. D. Thesis, University of Nagpur.

Mikaelsen, K. and Ahnstrom, G. 1968. Genetic effects of alkylating agents in barley. Influence of post storage metabolic stage and $\mathrm{pH}$ of mutagen solution. Hereditas 59: 353-374.

Nawaschin, M. 1933. Altern der Samen als Ursache der Mutationen. Planta 20: 233-243.

- and Gerassimowa, H. 1936. Natur und Ursachen der Mutationen 1. Das Verhalten und die Zytologie der Pflanzen die aus infolge Alterns mutierten Keimen stammen. Cytologia 7: 324-362.

Nichols, C. 1941. Spontaneocis chromosome aberrations in Allium. Genetics 26: 89-100.

Nilan, R. A. and Gunthardt, H. M. 1953. Studies on aged seeds III. R. S. of aged wheat seeds to X irradiation. Caryologia 8: 316-322.

Prasad, A. B. and Godward, M. B. E. 1974. Comparison of the developmental response of diploid and tetraploid phalaris following irradiation of the dry seeds IV. Elimination of chromosome aberrations. Mutation Research 25: 311-320.

Raghuvanshi, S. S. and Singh, D. N. 1977. Comparative radiosensitivity of diploid and autotetraploid Trigonella foenum graecum $\mathrm{L}$. Caryologia 30: 411-421.

Sax, K. 1941. Types and frequencies of chromosomal aberrations induced by $\mathrm{X}$ rays, Coldspring Harbor Symp. Quant. Biol, 9: 93-101. 